\title{
Pre-existing Cerebral Small Vessel Disease in Young Patients with Acute Ischemic Stroke caused by Large Artery Atherosclerosis or Small Artery Occlusion
}

\author{
Hui $\mathrm{Li}^{1, * *}$, Dan $\mathrm{Du}^{1, * *}$, Juan Chen ${ }^{2}$, Xiang Wang ${ }^{1, *}$, Yuanliang Xie ${ }^{1, *}$ \\ ${ }^{1}$ Department of Radiology, Central Hospital of Wuhan, Tongji Medical College, Huazhong University of Science and Technology, \\ No. 26 Shengli Street, Jiangan District, Wuhan City, Hubei Province 430014, China \\ ${ }^{2}$ Department of Neurology, Central Hospital of Wuhan, Tongji Medical College, Huazhong University of Science and Technology, \\ No. 26 Shengli Street, Jiangan District, Wuhan City, Hubei Province 430014, China
}

\author{
ARTICLE INFO \\ Article History \\ Received 22 March 2021 \\ Accepted 08 April 2021 \\ Keywords \\ Young \\ pre-existing cerebral small \\ vessel disease \\ acute ischemic stroke \\ large artery atherosclerosis \\ small artery occlusion
}

\begin{abstract}
Objective: To explore the characteristics of pre-existing Cerebral Small Vessel Disease (CSVD) in young patients with Acute Ischemic Stroke (AIS) caused by large artery atherosclerosis or small artery occlusion.

Methods: A total of 400 patients with suspected stroke or transient ischemic attack who aged 18-45 years old were included in this retrospective study. Demography data, vascular risk factors and primary CSVD were compared between patients with AIS and non-stroke or between patients with different subtypes of AIS.

Results: The levels of cerebrovascular risk factors were significantly higher in patients with AIS than those with non-stroke $(p<0.05)$. The majority of patients with large artery atherosclerotic stroke or small artery occlusive stroke were male. The age was slightly younger and the NIH stroke scale (NIHSS) score at admission were higher in large artery atherosclerotic stroke group than small artery occlusive stroke group. White matter hyperintensities, moderate and extensive enlarged perivascular space, 1-3 points of total score were more commonly observed in patients with AIS than those with non-stroke $(p<0.05)$. Male and diabetes were the risk factors of lacune infarctions $(p<0.05)$. Male, hypertension and primary CSVD were the risk factors of both of strokes $(p<0.05)$. The enlarged perivascular space notably increased the risk of large artery atherosclerotic stroke $(p=0.033)$.

Conclusion: Male, age, hypertension, diabetes and pre-existing CSVD were the risk factors of young patients with AIS. For young adults, once asymptomatic CSVD abnormalities were detected, cerebrovascular risk factors should be screened and preexisting prevention measures for stroke should be taken.
\end{abstract}

(C) 2021 The Authors. Publishing services by Atlantis Press International B.V. This is an open access article distributed under the CC BY-NC 4.0 license (http://creativecommons.org/licenses/by-nc/4.0/).

\section{INTRODUCTION}

The researches of stroke have long focused on the elderly, and the young stroke (18-45 years old) is a relatively neglected field. According to available data, the young stroke only account for less than $5 \%$ of all in western countries [1]. However, in developing countries, its proportion reaches $19-30 \%$ [2,3]. The incidence of young stroke is gradually increasing since the 1980s [4-6]. Researches on young stroke make more economic sense, because adults with young stroke are likely to be disabled during their most productive working years and have higher long-term mortality than their non-stroke peers $[3,7,8]$.

Lots of western studies have suggested that cardioembolism, carotid artery dissection and unexplained stroke may be the main etiological types of stroke in young people $[9,10]$. However,

"Corresponding authors.Email: xiangwang19125@126.com; drxieyuanliang@163.com ${ }^{\#} \mathrm{Hui} \mathrm{Li}$ and Dan Du are both the co-first author of this study.

Peer review under responsibility of the Association for Research into Arterial Structure and Physiology in some Chinese studies, large artery atherosclerosis and small artery occlusion are still considered as the most common causes of young stroke $[11,12]$. Stroke caused by small artery occlusion, also called lacunar infarction, is one of the pathological changes of Cerebral Small Vessel Disease (CSVD). CSVD often coexists with large artery atherosclerosis, and the latter has been proven to increase the risk of stroke in the elderly [13-15]. Whether CSVD increases the risk of stroke is still controversial. A previous multicenter study in Korea has shown that the presence and severity of CSVD increase the risk of stroke [16]. Nevertheless, another prospective, multicenter clinical trial, Stenting and Aggressive Medical Management for Preventing Recurrent Stroke in Intracranial Stenosis (SAMMPRIS), has indicated that CSVD do not increase the risk of stroke [17].

Cerebral small vessel disease is a pathology that affects microcirculation of the brain, and it is a major cause of cognitive impairment and dementia worldwide [18]. In recent years, CSVD is often found in youth without typical vascular risk factors during the assessment of benign neurological disorders, including headaches, dizziness and vertigo, nonspecific cognitive or mood disorders. 
Consequently, understanding the effect of asymptomatic CSVD on stroke is conducive in taking positive pre-existing prevention measures to reduce the risk of stroke. Until now, there are few studies on the relationship between CSVD and Acute Ischemic Stroke (AIS) in young people.

Therefore, the purpose of this study was to explore the characteristics of pre-existing CSVD in young patients with AIS caused by large artery atherosclerosis or small artery occlusion.

\section{SUBJECTS AND METHODS}

\subsection{Patients}

This study was approved by the local Medical Ethics Committee of Wuhan Central Hospital (NO. [2020]201). A total of 400 patients aged 18-45 years old who were treated in our hospital with suspected stroke or Transient Ischemic Attack (TIA) from January 2018 to January 2020 were enrolled in this retrospective study. Neuroimaging data of all patients were obtained from Picture Archiving and Communication Systems. Inclusion criteria: (1) Patients aged 18-45 years old; (2) Patients underwent brain Magnetic Resonance Imaging (MRI, including DWI, $\mathrm{T}_{1}$ and $\mathrm{T}_{2}$ weighted sequence), head and neck vascular imaging after admission; (3) Patients with complete cardiovascular data and a clear etiological diagnosis of stroke prior to discharge. Exclusion criteria: (1) Stroke caused by cardioembolism, undetermined cause, or other infrequent stroke etiologies (non-atherosclerotic arteriopathies, genetic disorders, coagulation disorders, systemic diseases, neoplasms, and infections; (2) Patients with hemorrhagic stroke; (3) Patients with brain tumor, infection, degeneration, metabolism, poisoning or mental disease; (4) Patients with pre-existing atherosclerotic cerebral infarction or cerebral hemorrhage; (5) Patients whose images with artifacts. Of the 1956 patients with suspected stroke or TIA, 1556 were excluded, and 400 patients were included in this study. The process of case screening was shown in Figure 1.

\subsection{Etiological Classification of Acute Ischemic Stroke and Definition of Pre-existing CSVD}

The diagnosis of AIS was determined by specific neuropathological symptoms and definitive MRI evidence. AISs were divided into five subtypes according to Trail of Org 10172 in Acute Stroke Treatment (TOAST) etiological classification, including large artery atherosclerotic stroke, stroke caused by cardioembolism, small artery occlusive stroke, other strokes with clear cause and strokes with undetermined cause. According to the main etiological characteristics of stroke in Chinese youth, we only selected patients with large artery atherosclerotic stroke and small artery occlusive stroke in the present study. Pre-existing CSVD was defined as one or more signs of chronic Lacune Infarctions (LI), White Matter Hyperintensities (WMH) and Enlarged Perivascular Space (EPVS). Due to the limited application of susceptibility weighted imaging in the assessment of AIS in most hospitals in China, we only selected CSVD signs (LI, WMH and EPVS) available from routine MRI sequences to ensure feasibility and transferability of the results on clinical practice.

\subsection{Clinical Data}

Clinical data, including demographic data, cerebrovascular risk factors, NIHSS scores and therapeutic approach after admission, were also collected. Demographic data included age and gender. Cerebrovascular risk factors covered blood pressure, blood glucose,

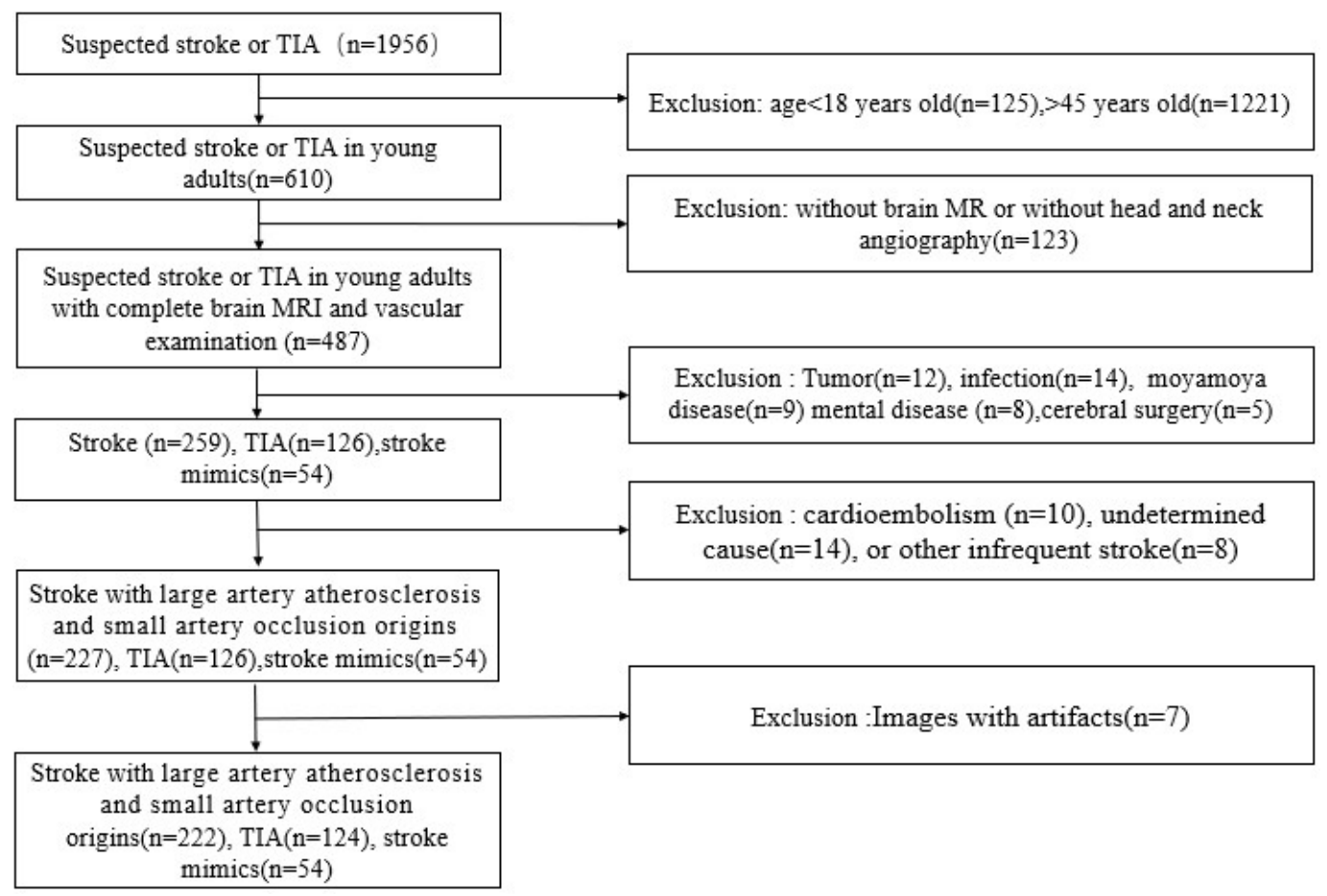

Figure $1 \mid$ The flow chart of research objects selection. 
Triglycerides (TG), Total Cholesterol (TC), High-density Lipoprotein Cholesterol (HDL-C), Low-density Lipoprotein Cholesterol (LDL-C) and homocysteine. Therapeutic approaches referred to oral antiplatelet drugs, intravenous thrombolysis, endovascular treatment and other treatments.

\subsection{MRI Acquisition}

1.5T Philips Ingenia scanner (Philips, The Netherlands) and 3.0T Siemens Skyra scanner (Siemens, Erlangen, Germany) were used for brain scan. The images contained $\mathrm{T}_{1}$-weighted, $\mathrm{T}_{2}$-weighted, $\mathrm{T}_{2}$ Fluid Attenuated Inversion Recovery ( $\mathrm{T}_{2}$-FLAIR), and DWI sequences. The sequence parameters of $1.5 \mathrm{~T}$ MRI were as follows: $\mathrm{T}_{1}$-weighted images $[$ Repeat Time $(\mathrm{TR})=2500 \mathrm{~ms}$, Echo Time $(\mathrm{TE})=$ $25 \mathrm{~ms}$, Field of View $(\mathrm{FOV})=220 \times 198 \mathrm{~mm}^{2}$, matrix $=320 \times 256$, slice thickness $=5 \mathrm{~mm}$, layer spacing $=1 \mathrm{~mm}$ ). $\mathrm{T}_{2}$-weighted images $\left(\mathrm{TR}=5000 \mathrm{~ms}, \mathrm{TE}=118 \mathrm{~ms}, \mathrm{FOV}=220 \times 199 \mathrm{~mm}^{2}\right.$, matrix $=320$ $\times 256$, slice thickness $=5 \mathrm{~mm}$, layer spacing $=1 \mathrm{~mm}) . \mathrm{T}_{2}$ FLAIR sequence $\left(\mathrm{TR}=9000 \mathrm{~ms}, \mathrm{TE}=172 \mathrm{~ms}, \mathrm{FOV}=220 \times 220 \mathrm{~mm}^{2}\right.$, matrix $=192 \times 256$, slice thickness $=5 \mathrm{~mm}$, layer spacing $=1 \mathrm{~mm}$ ). DWI sequences $\left(\mathrm{TR}=5000 \mathrm{~ms}, \mathrm{TE}=83 \mathrm{~ms}, \mathrm{FOV}=240 \times 240 \mathrm{~mm}^{2}\right.$, matrix $=128 \times 128$, slice thickness $=5 \mathrm{~mm}$, layer spacing $=1 \mathrm{~mm}$, $b$-value $=0,1000)$. The sequence parameters of 3.0T MRI were as follows: three-dimensional $\mathrm{T}_{1} \mathrm{WI}(\mathrm{TR}=2530 \mathrm{~ms}, \mathrm{TE}=3.43 \mathrm{~ms}$, $\mathrm{TI}=1100 \mathrm{~ms}, \mathrm{FOV}=256 \times 256 \mathrm{~mm}^{2}$, voxel size $=1 \times 1 \times 1.3 \mathrm{~mm}^{3}$, flip angle $=8^{\circ}, 144$ sagittal sections) were obtained on the sagittal plane by using the magnetized rapid gradient echo technology. $\mathrm{T}_{2} \mathrm{WI}\left(\mathrm{TR}=6000 \mathrm{~ms}, \mathrm{TE}=125 \mathrm{~ms}, \mathrm{FOV}=230 \times 230 \mathrm{~mm}^{2}\right.$, flip angle $=90^{\circ}$, slice thickness $=5 \mathrm{~mm}$, layer spacing $=1 \mathrm{~mm}, 80$ axial sections). $\mathrm{T}_{2}$-FLAIR (TR $=8500 \mathrm{~ms}, \mathrm{TE}=81 \mathrm{~ms}, \mathrm{FOV}=230 \times$ $230 \mathrm{~mm}^{2}$, flip angle $=150^{\circ}$, slice thickness $=5 \mathrm{~mm}$, layer spacing $=1 \mathrm{~mm}, 80$ axial sections). DWI sequences $(\mathrm{TR}=4040 \mathrm{~ms}, \mathrm{TE}=$ $64 \mathrm{~ms}, \mathrm{FOV}=220 \times 220 \mathrm{~mm}^{2}$, matrix $=128 \times 128$, slice thickness $=$ $5 \mathrm{~mm}$, layer spacing $=1 \mathrm{~mm}, b$-value $=0,1000)$.

\subsection{Pre-existing CSVD MRI Abnormalities Analysis}

Pre-existing CSVD MRI abnormalities were evaluated by an attending radiologist (Hui Li, MM) and a radiology professor (Yuanliang $\mathrm{Xie}, \mathrm{PhD}$ ). About 50 cases were randomly selected for consistency test. LI was defined as round or ovoid lesions with the diameter from 3 to $20 \mathrm{~mm}$ in the basal ganglia, internal capsule, centrum semiovale or brainstem, with CSF signal density on $\mathrm{T}_{2} \mathrm{WI}$ and $\mathrm{T}_{2}-$ FLAIR, without increased signal on DWI imaging [19]. The presence of LI was scored 1 , otherwise scored 0 . WMH was diagnosed and scored by the revised version of the visual scale of Fazekas [20]. The Fazekas scale included Periventricular White Matter Hypersignal (PVWMH) score and Deep White Matter Hypersignal (DWMH) score. PVWMH score was defined as follows: none (0, no lesions), mild (1, caps or a pencil-thin lining), moderate (2, smooth halo) and severe (3, irregular lesions extending to deep white matter). DWMH was scored as follows: none (0, no lesions), mild ( 1 , punctuate foci), moderate ( 2 , beginning confluent foci) and severe (3, large confluent lesions). EPVS was defined as small $(<3 \mathrm{~mm})$ punctate (if perpendicular to the plane of scan) or linear (if longitudinal to the plane of scan) lesions with signal intensity similar to that of cerebrospinal fluid on all sequence spaces and without a $\mathrm{T}_{2}$-hyperintense rim on FLAIR imaging. A three-category ordinal scale (mild, 0-10; moderate, 10-25; extensive, $>25$ ) was used to evaluate the severity of EPVS at basal ganglia level [21].

Total CSVD score was calculated based on LI, WMH, and EPVS referred to the ordinal scale developed by Klarenbeek et al. [22]. One point was awarded in the following cases: (1) one or more lacune infarctions were present; (2) DWMH Fazekas score 2 or 3, or PVWMH Fazekas score 3; (3) EPVS in the basal ganglia or centrum semiovale was scored 2 or 3 . Then the three subscores were summed up to generate a total CSVD score that ranged from 0 to 3 .

\subsection{Statistical Analysis}

SPSS version 22.0 (NY, USA) was used to perform the statistical analysis. The categorical/dichotomous variables were analyzed using $\chi^{2}$ test, and the linear-by-linear association was used for orderly classification variables. Continuous variables were analyzed by Mann-Whitney $U$-test. The impact of age, gender, risk factors on the risk of development of CSVD MRI abnormalities and the subtypes of AIS were assessed using logistic regression analysis. Odds Ratio (OR) and 95\% CI were reported. $p<0.05$ was considered to statistically significant. Kappa value was used to evaluate the consistency between the surveyors. Kappa value $<0.40$ indicated that the reliability of the data was poor, while kappa value $>0.75$ suggested high credibility.

\section{RESULTS}

\subsection{Consistency between the Surveyors}

The pre-existing CSVD MR abnormalities obtained twice by physician 1 (Hui Li, MD) were compared, and it showed a good reliability with kappa value of 0.81 for the presence of LI, 0.89 for PVWMH, 0.85 for DWMH, and 0.76 for EPVS. The consistency test between the surveyors also indicated satisfactory consistency with kappa values of 0.79 for the presence of LI, 0.87 for PVWMH, 0.89 for DWMH, and 0.85 for EPVS.

\subsection{Clinical Characteristics of Young Adults with AIS}

A total of 400 patients with suspicious stroke or TIA underwent brain MRI, head and neck angiography examination. About 222 patients (55.5\%) were diagnosed with AIS, including 130 (58.6\%) with large artery atherosclerotic stroke and $92(41.4 \%)$ with small artery occlusive stroke. There were 178 patients (44.5\%) with non-stroke, including $124(69.7 \%)$ with TIA and 54 (30.3\%) with stroke mimics.

Compared with non-stroke group, patients with AIS had higher blood pressure $(p=0.000)$, blood glucose $(p=0.000)$, TG $(p=0.000)$, TC $(p=0.000)$, HDL-C $(p=0.000)$, homocysteine $(p=0.000)$, NIHSS score $(p=0.012)$ at admission and LDL-C $(p=0.002)$. The majority of patients with AIS received antiplatelet therapy $(84.6 \%$ vs. $93.5 \%)$.

The majority of patients with large artery atherosclerotic stroke and small artery occlusive stroke were male (89.2\% vs. $87.0 \%)$. 
Table 1 Comparison of age, gender, vascular risk factors and treatments between ischemic stroke and non-stroke, as well as the subtypes of stroke

\begin{tabular}{|c|c|c|c|c|c|c|c|}
\hline \multirow[b]{2}{*}{ Clinical variables } & \multirow[b]{2}{*}{ Total $(n=400)$} & \multicolumn{4}{|c|}{ Acute ischemic stroke $(n=222)$} & \multirow[b]{2}{*}{$\begin{array}{l}\text { Non-stroke } \\
(n=178)\end{array}$} & \multirow[b]{2}{*}{$p$-value } \\
\hline & & $\begin{array}{c}\text { Large artery } \\
\text { atherosclerotic } \\
\text { stroke }(n=130)\end{array}$ & $\begin{array}{l}\text { Small artery } \\
\text { occlusive stroke } \\
(n=92)\end{array}$ & $p$-value & Total $(n=222)$ & & \\
\hline Age & $40(35-43)$ & $40.5(37-43)$ & $43(41-43)$ & $0.027^{*}$ & $42(39-43)$ & $39(30-43)$ & 0.105 \\
\hline Male (\%) & $294(73.5)$ & $116(89.2)$ & $80(87.0)$ & 0.604 & $196(88.3)$ & $98(55.1)$ & $0.000^{*}$ \\
\hline Blood pressure & $146(129-173)$ & $151(136-167)$ & $160(145-175)$ & 0.211 & $156(142-170)$ & $125(120-140)$ & $0.000^{*}$ \\
\hline Blood glucose & $5.42(4.86-6.89)$ & $5.74(5.01-9.66)$ & $5.23(4.64-6.40)$ & $0.023^{*}$ & $5.63(5.01-7.71)$ & $4.95(4.78-5.52)$ & $0.000^{*}$ \\
\hline Triglyceride & $1.62(1.04-2.44)$ & $1.86(1.25-2.64)$ & $2.11(1.2-2.22)$ & 0.537 & $1.87(1.20-2.32)$ & $1.52(0.73-0.97)$ & $0.000^{*}$ \\
\hline Total cholesterol & $4.68(4.00-5.24)$ & $4.89(4.1-5.2)$ & $4.64(4.2-5.26)$ & 0.108 & $4.83(4.17-5.21)$ & $4.5(3.92-5.18)$ & $0.000^{*}$ \\
\hline HDL-C & $1.10(0.95-1.25)$ & $1.1(0.97-1.21)$ & $1.13(0.83-1.45)$ & 0.107 & $1.11(0.96-1.25)$ & $1.22(1.08-1.43)$ & $0.002^{*}$ \\
\hline LDL-C & $2.89(2.33-3.78)$ & $3.06(2.64-3.60)$ & $2.91(2.51-3.28)$ & 0.419 & $2.97(2.64-3.52)$ & $2.56(2.23-3.29)$ & $0.000^{*}$ \\
\hline Homocysteine & $13.55(10.45-20)$ & $13.65(10.75-26.95)$ & $16.10(10.90-20.10)$ & 0.643 & $13.9(10.9-23.1)$ & $11.6(9.73-15.08)$ & $0.000^{*}$ \\
\hline NIHSS score & $3(1-5)$ & $5(2-7)$ & $2(0-2)$ & $0.003^{*}$ & $4(1-5)$ & $1(0-1)$ & $0.012^{*}$ \\
\hline \multicolumn{8}{|l|}{ Treatments (\%) } \\
\hline Intravenous thrombolysis & $4(1.0)$ & $2(1.5)$ & $2(2.1)$ & - & $4(1.8)$ & - & - \\
\hline Intraarterial thrombectomy & $6(1.5)$ & $6(4.6)$ & 0 & - & $6(2.7)$ & - & - \\
\hline Intraarterial thrombolysis & $4(1.0)$ & $4(3.1)$ & 0 & - & $4(1.8)$ & - & - \\
\hline Antiplatelet & $278(69.5)$ & $110(84.6)$ & $86(93.5)$ & - & $196(88.3)$ & - & - \\
\hline Others & $18(4.5)$ & $8(6.2)$ & $4(4.3)$ & - & $12(5.4)$ & - & - \\
\hline
\end{tabular}

$" p<0.05$.

Compared with patients with small artery occlusive stroke, the age of those with large artery atherosclerotic stroke was slightly younger $(p=0.027)$, the blood glucose $(p=0.023)$ and NIHSS score $(p=0.003)$ at admission were significantly higher. There were no significant differences in gender, systolic blood pressure, blood lipid and homocysteine at admission between the two subtypes of stroke $(p>0.05)$ (Table 1$)$.

\subsection{Pre-existing CSVD MRI Abnormalities in Young Ischemic Stroke}

Pre-existing CSVD MRI abnormalities were evaluated for the

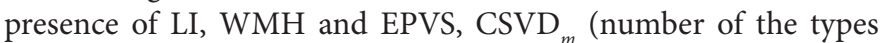
of CSVD imaging markers), LI score, WMH score, EPVS grading and CSVD total score. Pre-existing CSVD MRI abnormalities were present in $95.4 \%$ of patients with large artery atherosclerotic stroke and $93.5 \%$ with small artery occlusive stroke. Three and two kinds of pre-existing CSVD MRI abnormalities were more common in patients with large artery atherosclerotic stroke and small artery occlusive stroke, while one abnormality was rare. LI $(64.6 \%$ vs. $71.7 \%)$, WMH (89.2\% vs. $87.0 \%)$ and EPVS ( $83.1 \%$ vs. $82.6 \%)$ were commonly observed in both patients with large artery atherosclerotic stroke and small artery occlusive stroke, and most of them had mild to moderate WMH and EPVS.

The presence of pre-existing CSVD in patients with AIS was more common than non-stroke group ( $94.6 \%$ vs. $76.4 \%, p=0.000)$. Overall, WMH were found in $83 \%$ patients and there was significantly more common in patients with AIS compared to non-stroke group $(88.3 \%$ vs. $76.4 \%, p=0.011)$. Significantly fewer mild $(47.7 \%$ vs. $49.4 \%)$ but more moderate $(27.9 \%$ vs. $14.6 \%)$ and extensive (18.9\% vs. $12.4 \%)$ EPVS were observed in patients with AIS ( $p=$ $0.035)$. Patients with AIS got fewer 0 point $(12.6 \%$ vs. $20.2 \%)$ and more 1 point ( $45.9 \%$ vs. $31.5 \%), 2$ points ( $30.6 \%$ vs. $22.5 \%)$ and 3 points $(5.4 \%$ vs. $2.2 \%)$ of total score than non-stroke group ( $p=$ 0.014 ) (Table 2).

\subsection{Relationship between Pre-existing CSVD MRI Abnormalities and Age, Gender, Risk Factors, Subtypes of Ischemic Stroke}

Pre-existing CSVD MRI abnormalities were observed in almost $86.5 \%$ of all subjects (LI 68.2\%, WMH 96.0\%, EPVS $86.1 \%$ ), and $56.1 \%$ of them had three types and $38.2 \%$ had two types. CSVD MRI abnormalities were increased with age. LI were observed in $70 \%$ patients over 35 years old, the OR for developing LI was 10.61 times $(p=0.001)$ compared to the patients under 35 years old. The presence of WMH and EPVS accounted for $92.7 \%$ and $84.0 \%$ of patients over 35 years old, and the OR for developing WMH and EPVS were 4.598 times $(p=0.026)$ and 5.205 times $(p=0.048)$ respectively compared with those under 35 years old. LI were present in $64.6 \%$ of male patients. Male was more likely to develop lacunar infarction than female up to 4.12 times $(p=0.017) .77 \%$ of diabetic patients developed LI up to 5.58 times $(p=0.005)$ compared with non-diabetic patients (Table 3 and Figure 2).

Male was 4.424 and 17.835 times more likely to develop large artery atherosclerotic stroke (4.424 times, $p=0.017$ ) and small artery occlusive stroke (17.835 times, $p=0.001)$ compared to female. Hypertension significantly increased the risk of large artery atherosclerotic stroke (7.198 times, $p=0.000)$ and small artery occlusive stroke (23.119 times, $p=0.000)$. For large artery atherosclerotic stroke and small artery occlusive stroke, HDL-C and hyperhomocysteinemia were protective factors. The pre-existing CSVD could both increase the risk of large artery atherosclerotic stroke (5.249 times, $p=0.031$ ) and small vessel occlusive stroke (3.182 times, $p=$ 0.042). The pre-existing EPVS obviously increased the risk of large artery atherosclerotic stroke (9.989 times, $p=0.033$ ) (Table 4).

\section{DISCUSSION}

In the past, researches on young stroke mainly focused on exploring its risk factors. Young CSVD is mostly presented in the form 
Table 2 Comparison of pre-existing CSVD MRI abnormalities between ischemic stroke and non-stroke, as well as subtypes of stroke

\begin{tabular}{|c|c|c|c|c|c|c|c|}
\hline \multirow[b]{2}{*}{ CSVD abnormalities } & \multirow[b]{2}{*}{ Total $(n=400)$} & \multicolumn{4}{|c|}{ Acute ischemic stroke $(n=222)$} & \multirow[b]{2}{*}{$\begin{array}{c}\text { Non-stroke } \\
(n=178)\end{array}$} & \multirow[b]{2}{*}{$p$-value } \\
\hline & & $\begin{array}{c}\text { Large artery } \\
\text { atherosclerotic } \\
\text { stroke }(n=130)\end{array}$ & $\begin{array}{l}\text { Small artery } \\
\text { occlusive stroke } \\
(n=92)\end{array}$ & $p$-value & Total $(n=222)$ & & \\
\hline Pre-existing CSVD (\%) & $346(86.5)$ & $124(95.4)$ & $86(93.5)$ & 0.750 & $210(94.6)$ & $136(76.4)$ & $0.000^{*}$ \\
\hline $\begin{array}{l}\operatorname{CSVD}_{m}(\%) \\
1 \\
2 \\
3\end{array}$ & $\begin{array}{c}20(5.8) \\
132(38.2) \\
194(56.0)\end{array}$ & $\begin{array}{l}12(9.2) \\
42(32.3) \\
70(53.8)\end{array}$ & $\begin{array}{c}2(2.2) \\
32(34.8) \\
52(56.5)\end{array}$ & $\begin{array}{l}0.192 \\
- \\
- \\
-\end{array}$ & $\begin{array}{c}14(6.3) \\
74(33.3) \\
122(55.0)\end{array}$ & $\begin{array}{c}6(3.4) \\
58(32.6) \\
72(40.4)\end{array}$ & $\begin{array}{c}0.664 \\
- \\
- \\
-\end{array}$ \\
\hline $\begin{array}{l}\text { LI (\%) } \\
\text { WMH (\%) } \\
\text { EPVS (\%) } \\
\text { CSVD score }\end{array}$ & $\begin{array}{l}236(68.2) \\
332(96) \\
298(86.1)\end{array}$ & $\begin{array}{r}84(64.6) \\
116(89.2) \\
108(83.1)\end{array}$ & $\begin{array}{l}66(71.7) \\
80(87.0) \\
76(82.6)\end{array}$ & $\begin{array}{l}0.156 \\
0.745 \\
0.783\end{array}$ & $\begin{array}{l}150(67.6) \\
196(88.3) \\
184(82.9)\end{array}$ & $\begin{array}{r}86(48.3) \\
136(76.4) \\
114(64.0)\end{array}$ & $\begin{array}{l}0.110 \\
0.011^{*} \\
0.318\end{array}$ \\
\hline $\begin{array}{l}\text { LI score } \\
0 \\
1\end{array}$ & $\begin{array}{l}110(31.8) \\
236(68.2)\end{array}$ & $\begin{array}{l}40(30.8) \\
84(64.6)\end{array}$ & $\begin{array}{l}20(21.7) \\
66(71.7)\end{array}$ & $\begin{array}{l}0.157 \\
- \\
-\end{array}$ & $\begin{array}{r}60(27.0) \\
150(67.6)\end{array}$ & $\begin{array}{l}86(48.3) \\
50(28.1) \\
86(48.3)\end{array}$ & $\begin{array}{c}0.110 \\
- \\
-\end{array}$ \\
\hline $\begin{array}{l}\text { WMH score } \\
0 \\
1 \text { and } 2 \\
3 \text { and } 4 \\
5 \text { and } 6\end{array}$ & $\begin{aligned} 14 & (4.0) \\
288 & (83.2) \\
36 & (10.4) \\
8 & (2.3)\end{aligned}$ & $\begin{array}{c}8(6.2) \\
104(80.0) \\
8(6.2) \\
4(3.1)\end{array}$ & $\begin{array}{c}6(6.5) \\
66(71.7) \\
12(13.0) \\
2(2.2)\end{array}$ & $\begin{array}{l}0.478 \\
- \\
- \\
- \\
-\end{array}$ & $\begin{array}{c}14(6.3) \\
170(76.6) \\
20(9.0) \\
6(2.7)\end{array}$ & $\begin{array}{c}0(0) \\
118(66.3) \\
16(9.0) \\
2(1.1)\end{array}$ & $\begin{array}{c}0.241 \\
- \\
- \\
- \\
-\end{array}$ \\
\hline $\begin{array}{l}\text { EPVS grading } \\
\qquad 1 \\
2 \\
3\end{array}$ & $\begin{array}{r}194(56.1) \\
88(25.4) \\
64(18.5)\end{array}$ & $\begin{array}{l}62(47.7) \\
36(27.7) \\
26(20.0)\end{array}$ & $\begin{array}{l}44(47.8) \\
26(28.3) \\
16(17.4)\end{array}$ & $\begin{array}{l}0.914 \\
- \\
- \\
-\end{array}$ & $\begin{array}{r}106(47.7) \\
62(27.9) \\
42(18.9)\end{array}$ & $\begin{array}{l}88(49.4) \\
26(14.6) \\
22(12.4)\end{array}$ & $\begin{array}{c}0.035^{*} \\
- \\
- \\
-\end{array}$ \\
\hline $\begin{array}{l}\text { Total score } \\
0 \\
1 \\
2 \\
3\end{array}$ & $\begin{array}{c}64(18.5) \\
158(45.7) \\
108(31.2) \\
16(4.6)\end{array}$ & $\begin{array}{c}22(16.9) \\
54(41.5) \\
42(32.3) \\
6(4.6)\end{array}$ & $\begin{array}{c}6(6.5) \\
48(52.2) \\
26(28.3) \\
6(6.5)\end{array}$ & $\begin{array}{l}0.292 \\
- \\
- \\
- \\
-\end{array}$ & $\begin{array}{r}28(12.6) \\
102(45.9) \\
68(30.6) \\
12(5.4)\end{array}$ & $\begin{array}{c}36(20.2) \\
56(31.5) \\
40(22.5) \\
4(2.2)\end{array}$ & $\begin{array}{c}0.014^{*} \\
- \\
- \\
- \\
-\end{array}$ \\
\hline
\end{tabular}

" $p<0.05$.

Table 3 Binary logistic regression analysis for the risk factors of LI, WMH and EPVS

\begin{tabular}{|c|c|c|c|c|c|c|c|c|c|}
\hline \multirow{2}{*}{ Variables } & \multicolumn{3}{|c|}{ LI } & \multicolumn{3}{|c|}{ WMH } & \multicolumn{3}{|c|}{ EPVS } \\
\hline & No. (\%) & $\begin{array}{l}\text { Adjusted OR } \\
(95 \% \mathrm{CI})\end{array}$ & $p$-value & No. (\%) & $\begin{array}{l}\text { Adjusted OR } \\
(95 \% \mathrm{CI})\end{array}$ & $p$-value & No. (\%) & $\begin{array}{c}\text { Adjusted OR } \\
(95 \% \mathrm{CI})\end{array}$ & $p$-value \\
\hline >35 (Yes vs. No) & $210(70.0)$ & $10.61(2.54-44.29)$ & $0.001^{*}$ & $278(92.7)$ & $4.598(1.365-12.258)$ & $0.026^{*}$ & $252(84.0)$ & $5.205(1.013-26.751)$ & $0.048^{*}$ \\
\hline Male (Yes vs. No) & $190(64.6)$ & $4.12(1.29-13.18)$ & $0.017^{*}$ & $254(86.4)$ & $0.904(0.174-4.688)$ & 0.904 & $230(78.2)$ & $0.929(0.133-6.471)$ & 0.941 \\
\hline Diabetes (Yes vs. No) & $94(77.0)$ & $5.58(1.67-18.62)$ & $0.005^{*}$ & $110(90.2)$ & $0.317(0.091-1.099)$ & 0.070 & $106(86.9)$ & $1.907(0.289-12.583)$ & 0.503 \\
\hline $\begin{array}{l}\text { Hypertension (Yes } \\
\text { vs. No) }\end{array}$ & $170(69.1)$ & $0.644(0.207-2.003)$ & 0.447 & $228(92.7)$ & $0.541(0.110-2.658)$ & 0.449 & $208(84.6)$ & $0.290(0.047-1.786)$ & 0.182 \\
\hline $\begin{array}{l}\text { High triglycerides } \\
\text { (Yes vs. No) }\end{array}$ & $118(67.8)$ & $1.479(0.507-4.311)$ & 0.474 & $152(87.4)$ & $1.255(0.377-4.175)$ & 0.711 & $142(81.6)$ & $2.850(0.525-15.483)$ & 0.225 \\
\hline $\begin{array}{l}\text { High total cholesterol } \\
\text { (Yes vs. No) }\end{array}$ & $32(72.7)$ & $1.938(0.293-12.826)$ & 0.493 & $40(90.9)$ & $0.993(0.200-4.944)$ & 0.993 & $38(86.4)$ & $1.835(0.327-11.684)$ & 0.482 \\
\hline $\begin{array}{l}\text { Hyperhomocystein- } \\
\text { emia (Yes vs. No) }\end{array}$ & $44(78.6)$ & $2.390(0.775-7.368)$ & 0.129 & $52(92.9)$ & $1.349(0.893-2.037)$ & 0.155 & $50(89.3)$ & $1.231(0.231-6.562)$ & 0.808 \\
\hline
\end{tabular}

${ }^{*} p<0.05$.

of asymptomatic, which is a neglected field. There are few studies to explore the relationship between pre-existing CSVD and stroke. A post hoc analysis in older people, SAMMPRIS trial, showed a lack of association between CSVD and stroke recurrence [17]. However, our study showed that more than $90 \%$ of young patients with AIS (95.4\% of large artery atherosclerotic stroke and $93.5 \%$ of small artery occlusive stroke) were co-existed with
CSVD. An explanation for high frequency of young CSVD with AIS may be that patients are more susceptible to vascular risk factors than other people, and there might be a genetic predisposition to cardiovascular disease. Another possibility is that patients have been exposed to vascular risk factors for longer time than healthy controls [23]. Blood pressure, as the most common risk factor of cerebrovascular disease, has showed its association with subtle 

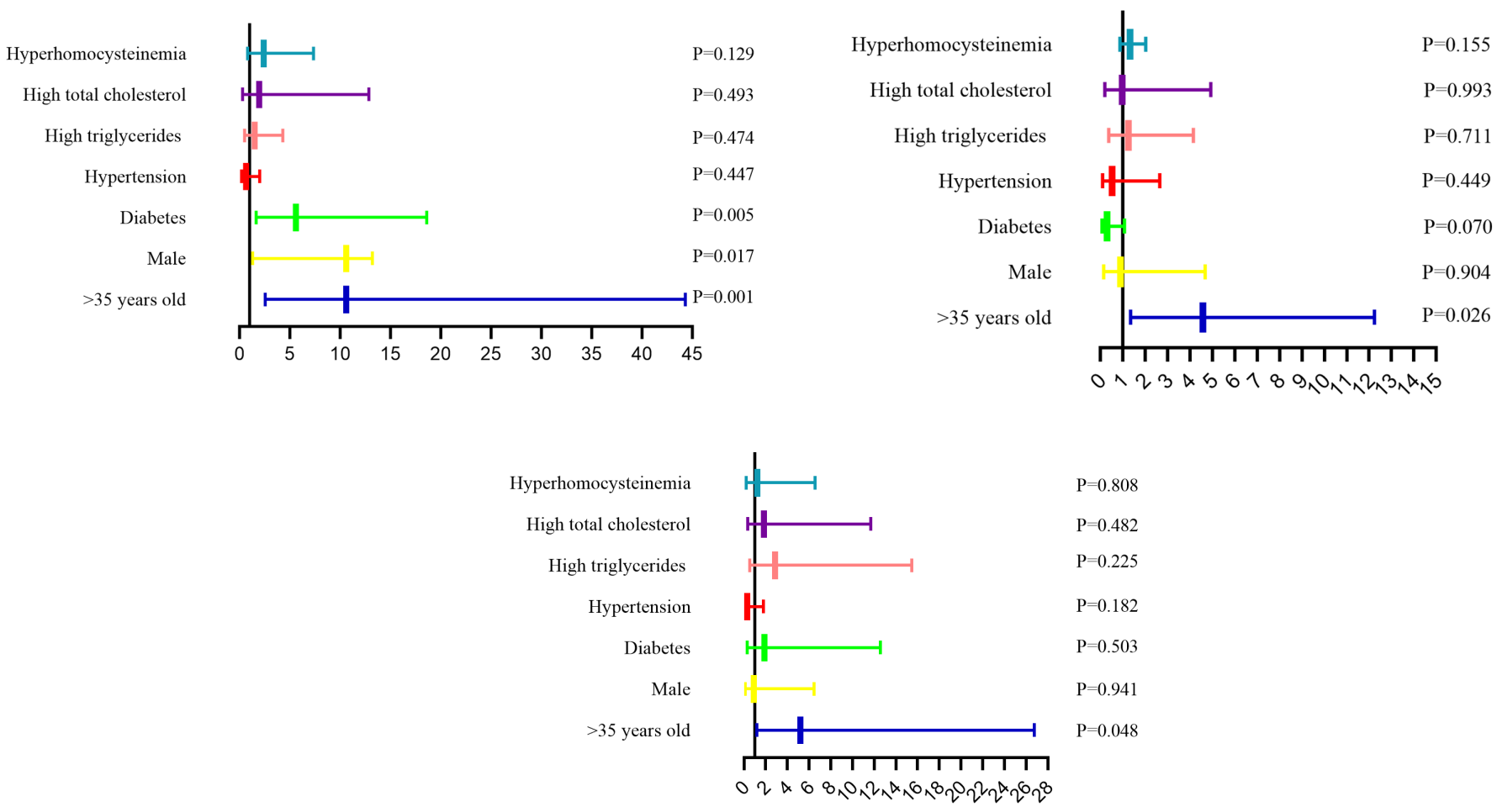

Figure 2 The analysis of risk factors for development of LI, WMH and EPVS, respectively. $p<0.05$ presented independent risk factors.

Table 4 Multiple logistic regression analysis for the risk factors of subtypes of ischemic stroke

\begin{tabular}{|c|c|c|c|c|c|}
\hline \multirow{2}{*}{ Variables } & \multicolumn{2}{|c|}{ Large artery atherosclerotic stroke $(n=130)$} & \multicolumn{2}{|c|}{ Small artery occlusive stroke $(n=92)$} & \multirow{2}{*}{$\begin{array}{l}\text { Non-stroke } \\
(n=178)\end{array}$} \\
\hline & OR $(95 \% \mathrm{CI})$ & $p$-value & OR (95\% CI) & $p$-value & \\
\hline$>35$ years old (Yes vs. No) & $0.519(0.136-1.976)$ & 0.336 & $1.844(0.359-9.461)$ & 0.463 & 1 \\
\hline Male (Yes vs. No) & $4.424(1.309-14.955)$ & $0.017^{*}$ & $17.835(3.136-101.424)$ & $0.001^{*}$ & 1 \\
\hline Diabetes (Yes vs. No) & $1.801(0.592-5.484)$ & 0.300 & $1.026(0.361-2.920)$ & 0.961 & 1 \\
\hline Hypertension (Yes vs. No) & $7.198(2.509-20.653)$ & $0.000^{*}$ & $23.119(6.877-77.721)$ & $0.000^{*}$ & 1 \\
\hline High triglycerides (Yes vs. No) & $2.204(0.867-5.603)$ & 0.097 & $1.277(0.504-3.232)$ & 0.606 & 1 \\
\hline High total cholesterol (Yes vs. No) & $0.178(0.043-0.737)$ & $0.017^{*}$ & $0.228(0.072-0.725)$ & $0.012^{*}$ & 1 \\
\hline Hyperhomocysteinemia (Yes vs. No) & $0.298(0.107-0.829)$ & $0.020^{*}$ & $0.319(0.120-0.848)$ & $0.022^{*}$ & 1 \\
\hline Pre-existing CSVD (Yes vs. No) & $5.249(1.684-10.631)$ & $0.031^{*}$ & $3.182(1.202-7.248)$ & $0.042^{*}$ & 1 \\
\hline LI (Yes vs. No) & $0.561(0.183-1.718)$ & 0.311 & $2.213(0.703-6.963)$ & 0.175 & 1 \\
\hline WMH (Yes vs. No) & $4.021(0.153-6.294)$ & 0.320 & $3.984(0.389-5.241)$ & 0.424 & 1 \\
\hline EPVS (Yes vs. No) & $9.989(1.208-82.576)$ & $0.033^{*}$ & $3.084(0.501-18.999)$ & 0.225 & 1 \\
\hline
\end{tabular}

" $p<0.05$.

vascular brain injury so as to already reduce cerebral integrity in very early life [24].

Furthermore, this study indicated that, in young adults, the presence of pre-existing CSVD significantly increased the risk of large artery atherosclerotic stroke and small artery occlusion stroke. Similar results have been reported in a multicenter study from Korea [16]. However, the latter study focused on older people. The mechanism of pre-existing CSVD on stroke may be as follows. First, small vessel diseases increase media, lumen ratio and rarefaction in the microcirculation, leading to increased peripheral resistance [25]. The increase of peripheral resistance is the main factor leading to the increase of mean blood pressure, which will increase the stiffness and atherosclerosis of the great arteries [26]. Second, chronic CSVD damages collaterals and impairs the compensatory mechanism of artery occlusion that leads to higher risk of AIS [27].

Majority of young people with large artery atherosclerotic stroke and small artery occlusive stroke had two or three kinds of CSVD abnormalities at least. In this study, compared with non-stroke patients, patients with AIS had a higher proportion of moderate to severe EPVS, and the presence of EPVS significantly increased the risk of large artery atherosclerotic stroke. This is contrary to the conclusion of Zhang et al. [28]. The inconsistent results might be related to the selection of case population. Our study population was young people aged 18-45 years old, and there might be fewer mixed influence factors on EPVS, including age, systemic diseases and other related factors. On the contrary, 
Wang's [29] latest study suggested that the severity of EPVS was related to intracranial and extracranial atherosclerosis, and Staals et al. [30] believed that the presence of EPVS was related to different stroke subtypes. The results of these studies were consistent with ours on some degree.

For young adults over 35 years old, the risk of LI, WMH and EPVS increased four to 10 times, which demonstrated that CSVD abnormalities were increased with age. It turned out that age was also an important risk factor for CSVD in young people, just like elderly CSVD $[31,32]$. In addition, gender was a risk factor for LI in young adults. Among males, the proportion of smokers and drinkers was significantly higher [33-35], indicating that males were more frequently exposed to the risk factors of CSVD and had a greater risk of lacunar infarctions. Type 2 Diabetes Mellitus was also considered as an important risk factor for CSVD in this study, which was consistent with the epidemiological and pathogenesis studies of CSVD in recent years [36-38], suggesting that diabetes mellitus was also a risk factor for LI. The causal relationship between diabetes and lacunar is yet to be determined, and a genetic predisposition to diabetes, maybe is related to lacunar stroke [36].

In young adults, hypertension is also a common risk factor for large artery atherosclerotic stroke and small artery occlusive stroke. In this study, $79.3 \%(176 / 222)$ of patients with young stroke had hypertension. The causes of hypertension in young people may be related to genetic factors, unhealthy diet and rest, and high intensity mental pressure. Chronic hypertension can lead to vascular wall atherosclerosis, fibrinoid necrosis, hyaline degeneration, microaneurysms and other pathological changes, leading to stroke $[39,40]$.

The advantage of our study is that it has showed that pre-existing CSVD is very common in young adults with large atherosclerotic and small artery occlusive stroke, and pre-existing CSVD significantly increases the risk of ischemic stroke. Previous studies do not do specifical study among young population in the relationship of CSVD and stroke, and people may ignore the influence of asymptomatic CSVD on young stroke. Once asymptomatic CSVD are detected in young people, further screening for cerebrovascular disease risk factors and pre-existing stroke prevention measures is required. The shortcomings of this study are that it is a single-center study and the sample size is small, which could only explain the relationship of CSVD, stroke types and risk factors in a small scope of youths, a larger multi-center prospective study is needed to provide more insight in this proposition, and further clarify CSVD and the pathogenesis of stroke and causality.

\section{CONCLUSION}

In conclusion, this study showed that young adults with large artery atherosclerotic stroke or small artery occlusive stroke often coexisted with CSVD abnormalities. The presence of pre-existing CSVD in young patients increased the risk of large artery atherosclerotic stroke or small artery occlusive stroke, which indicated that CSVD may be involved in the pathogenesis of atherosclerosis. For young adults, once asymptomatic CSVD abnormalities are detected, cerebrovascular risk factors should be screened and pre-existing prevention measures for stroke should be taken.

\section{CONFLICTS OF INTEREST}

The authors declare they have no conflicts of interest.

\section{AUTHORS' CONTRIBUTION}

HL and DD carried out the study, participated in collecting data, statistical analysis, and drafted the manuscript. JC participated in collecting data and provided guidance on case classification. XW and YX participated in its design and helped to draft the manuscript. All authors read and approved the final manuscript.

\section{FUNDING}

No financial support was provided.

\section{ETHICAL STANDARDS}

This study was approved by the local Medical Ethics Committee of Wuhan Central Hospital (NO. [2020]201).

\section{REFERENCES}

[1] Nencini P, Inzitari D, Baruffi MC, Fratiglioni L, Gagliardi R, Benvenuti L, et al. Incidence of stroke in young adults in Florence, Italy. Stroke 1988;19:977-81.

[2] Radhakrishnan K, Ashok PP, Sridharan R, Mousa ME. Stroke in the young: incidence and pattern in Benghazi, Libya. Acta Neurol Scand 1986;73:434-8.

[3] Kittner SJ, McCarter RJ, Sherwin RW, Sloan MA, Stern BJ, Johnson CJ, et al. Black-white differences in stroke risk among young adults. Stroke 1993;24:I13-I15; discussion I20- I1.

[4] Feigin VL, Norrving B, Mensah GA. Global burden of stroke. Circ Res 2017;120:439-48.

[5] Putaala J. Ischemic stroke in the young: current perspectives on incidence, risk factors, and cardiovascular prognosis. Eur Stroke J 2016;1:28-40.

[6] Smajlović D. Strokes in young adults: epidemiology and prevention. Vasc Health Risk Manag 2015;11:157-64.

[7] Varona JF. Long-term prognosis of ischemic stroke in young adults. Stroke Res Treat 2010;2011:879817.

[8] Naess H, Tatlisumak T, Kõrv J. Stroke in the young 2012. Stroke Res Treat 2012;2012:656913.

[9] Renna R, Pilato F, Profice P, Della Marca G, Broccolini A, Morosetti R, et al. Risk factor and etiology analysis of ischemic stroke in young adult patients. J Stroke Cerebrovasc Dis 2014; 23:e221-e7.

[10] Yesilot Barlas N, Putaala J, Waje-Andreassen U, Vassilopoulou S, Nardi K, Odier C, et al. Etiology of first-ever ischaemic stroke in European young adults: the 15 cities young stroke study. Eur J Neurol 2013;20:1431-9.

[11] Li F, Yang L, Yang R, Xu W, Chen FP, Li N, et al. Ischemic stroke in young adults of northern China: characteristics and risk factors for recurrence. Eur Neurol 2017;77:115-22. 
[12] Ge JJ, Xing YQ, Chen HX, Wang LJ, Cui L. Analysis of young ischemic stroke patients in northeast China. Ann Transl Med 2020;8:3.

[13] Pan Y, Meng X, Jing J, Li H, Zhao X, Liu L, et al. Association of multiple infarctions and ICAS with outcomes of minor stroke and TIA. Neurology 2017;88:1081-8.

[14] Liu L, Wong KSL, Leng X, Pu Y, Wang Y, Jing J, et al. Dual antiplatelet therapy in stroke and ICAS: subgroup analysis of chance. Neurology 2015;85:1154-62.

[15] Wang Y, Zhao X, Liu L, Soo YOY, Pu Y, Pan Y, et al. Prevalence and outcomes of symptomatic intracranial large artery stenoses and occlusions in China: the Chinese intracranial atherosclerosis (CICAS) study. Stroke 2014;45:663-9.

[16] Nam KW, Kwon HM, Lim JS, Han MK, Nam H, Lee YS. The presence and severity of cerebral small vessel disease increases the frequency of stroke in a cohort of patients with large artery occlusive disease. PLoS One 2017;12:e0184944.

[17] Kwon HM, Lynn MJ, Turan TN, Derdeyn CP, Fiorella D, Lane BF, et al. Frequency, risk factors, and outcome of coexistent small vessel disease and intracranial arterial stenosis: results from the stenting and aggressive medical management for preventing recurrent stroke in intracranial stenosis (SAMMPRIS) trial. JAMA Neurol 2016;73:36-42.

[18] Arba F, Testa GD, Limbucci N, Nappini S, Renieri L, Pracucci $\mathrm{G}$, et al. Small vessel disease and clinical outcomes after endovascular treatment in acute ischemic stroke. Neurol Sci 2019;40:1227-35.

[19] Wardlaw JM, Smith EE, Biessels GJ, Cordonnier C, Fazekas F, Frayne R, et al. Neuroimaging standards for research into small vessel disease and its contribution to ageing and neurodegeneration. Lancet Neurol 2013;12:822-38.

[20] Fazekas F, Chawluk JB, Alavi A, Hurtig HI, Zimmerman RA. MR signal abnormalities at $1.5 \mathrm{~T}$ in Alzheimer's dementia and normal aging. AJR Am J Roentgenol 1987;149:351-6.

[21] Klarenbeek P, van Oostenbrugge RJ, Lodder J, Rouhl RPW, Knottnerus ILH, Staals J. Higher ambulatory blood pressure relates to enlarged Virchow-Robin spaces in first-ever lacunar stroke patients. J Neurol 2013;260:115-21.

[22] Klarenbeek P, van Oostenbrugge RJ, Rouhl RPW, Knottnerus ILH, Staals J. Ambulatory blood pressure in patients with lacunar stroke: association with total MRI burden of cerebral small vessel disease. Stroke 2013;44:2995-9.

[23] Arntz RM, van den Broek SMA, van Uden IWM, Ghafoorian M, Platel B, Rutten-Jacobs LCA, et al. Accelerated development of cerebral small vessel disease in young stroke patients. Neurology 2016;87:1212-19.

[24] Maillard P, Seshadri S, Beiser A, Himali JJ, Au R, Fletcher E, et al. Effects of systolic blood pressure on white-matter integrity in young adults in the Framingham Heart Study: a cross-sectional study. Lancet Neurol 2012;11:1039-47.
[25] Xu WH. Large artery: an important target for cerebral small vessel diseases. Ann Transl Med 2014;2:78.

[26] Laurent S, Briet M, Boutouyrie P. Large and small artery crosstalk and recent morbidity-mortality trials in hypertension. Hypertension 2009;54:388-92.

[27] Lin MP, Brott TG, Liebeskind DS, Meschia JF, Sam K, Gottesman RF. Collateral recruitment is impaired by cerebral small vessel disease. Stroke 2020;51:1404-10.

[28] Zhang J, Han F, Liang X, Li M, Zhang D, Zhai F, et al. Lacune and large perivascular space: two kinds of cavities are of different risk factors and stroke risk. Cerebrovasc Dis 2020;49:522-30.

[29] Wang H, Nie ZY, Liu M, Li RR, Huang LH, Lu Z, et al. Clinical characteristics of perivascular space and brain CT perfusion in stroke-free patients with intracranial and extracranial atherosclerosis of different extents. Ann Transl Med 2020;8:215.

[30] Staals J, Makin SDJ, Doubal FN, Dennis MS, Wardlaw JM. Stroke subtype, vascular risk factors, and total MRI brain small-vessel disease burden. Neurology 2014;83:1228-34.

[31] Han F, Zhai FF, Wang Q, Zhou LX, Ni J, Yao M, et al. Prevalence and risk factors of cerebral small vessel disease in a Chinese population-based sample. J Stroke 2018;20:239-46.

[32] Zhou LW, Panenka WJ, AlMomen G, Gicas KM, Thornton AE, Jones AA, et al. Cerebral small vessel disease, risk factors, and cognition in tenants of precarious housing. Stroke 2020;51: 3271-8.

[33] Martínez-Sánchez P, Fuentes B, Fernández-Domínguez J, OrtegaCasarrubios Mde L, Aguilar-Amar MJ, Abenza-Abildúa MJ, et al. Young women have poorer outcomes than men after stroke. Cerebrovasc Dis 2011;31:455-63.

[34] Zhang B, Pu S, Zhang W, Yang N, Shen G, Yin J, et al. Sex differences in risk factors, etiology, and short-term outcome of cerebral infarction in young patients. Atherosclerosis 2011;216:420-5.

[35] Putaala J, Metso AJ, Metso TM, Konkola N, Kraemer Y, Haapaniemi E, et al. Analysis of 1008 consecutive patients aged 15 to 49 with first-ever ischemic stroke: the Helsinki young stroke registry. Stroke 2009;40:1195-203.

[36] Liu J, Rutten-Jacobs L, Liu M, Markus HS, Traylor M. Causal impact of type 2 diabetes mellitus on cerebral small vessel disease: a Mendelian randomization analysis. Stroke 2018;49:1325-31.

[37] van Harten B, de Leeuw FE, Weinstein HC, Scheltens P, Biessels GJ. Brain imaging in patients with diabetes: a systematic review. Diabetes Care 2006;29:2539-48.

[38] Brundel M, Kappelle LJ, Biessels GJ. Brain imaging in type 2 diabetes. Eur Neuropsychopharmacol 2014;24:1967-81.

[39] Kashgarian M. Pathology of small blood vessel disease in hypertension. Am J Kidney Dis 1985;5:A104-A10.

[40] Siriratnam P, Godfrey A, O’Connor E, Pearce D, Hu CC, Low A, et al. Prevalence and risk factors of ischaemic stroke in the young: a regional Australian perspective. Intern Med J 2020;50: 698-704. 